\title{
USO DE EXTRATOS DE PLANTAS NO COMBATE A CEPAS DE Escherichia coli CAUSADORAS DE DIARREIA NEONATAL BOVINA
}

\author{
ROSALEM, Marcela ${ }^{1}$ \\ OLIVEIRA, Luciano Ricardo de ${ }^{2}$ \\ DAMIÃO, Isabela Lara ${ }^{3}$ \\ FERREIRA, Beatriz Dombrovski de Paula ${ }^{4}$ \\ FRIAS, Danila Fernanda Rodrigues ${ }^{5}$
}

\begin{abstract}
\begin{tabular}{lll}
\hline Recebido em: 2020.03 .19 & Aprovado em: 2020.09 .16 & ISSUE DOI: $10.3738 / 1982.2278 .3760$
\end{tabular}
RESUMO: O presente trabalho avaliou o uso de extratos de plantas para controle de Escherichia coli causadora de diarreia neonatal bovina. Foram utilizadas duas cepas de E. coli isoladas de amostras de diarreia neonatal. Após a identificação da bactéria, foi realizada a verificação da susceptibilidade antimicrobiana in vitro, seguido da realização do cálculo do índice de resistência múltipla aos antimicrobianos (IRMA). Foram testados os extratos etanólicos de: Goiaba, Pitanga, Fruta do conde, Acerola, Graviola, Romã, Neem, Jenipapo, Lichia, Tamarindo, Jambo e Cidra. A concentração inibitória mínima (CIM) dos extratos foi determinada utilizando-se o método de microdiluição em placas, onde foram testadas em várias concentrações. A concentração bactericida mínima (CBM) foi determinada após a obtenção dos resultados da concentração inibitória mínima, e em seguida foi calculada a curva de sobrevivência. As duas cepas testadas apresentaram maior resistência aos antibióticos Ceftazidima, Amicacina, Tobramicina, Tetraciclina, Amoxicilina + Clavulanato, Cefoxitina e Cefotaxima e apresentaram multirresistência. Com relação a CIM e CBM, os extratos que demonstraram ação antibacteriana foram Pitanga, Tamarindo, Romã, Jambo e Jenipapo. Quando avaliou-se a curva de sobrevivência, destacou-se frente aos dois patógenos estudados os extratos de Pitanga, Tamarindo, Romã. Concluiu-se que as cepas de E. coli testadas apresentaram multirresistência, o que demonstra o uso indiscriminado de antibióticos, e que o uso de extratos de plantas mostrou-se eficaz nas concentrações pesquisadas, podendo ser utilizados como tratamentos alternativos contra diarreia neonatal bovina causada por E. coli.
\end{abstract}

Palavras-chave: Concentração Inibitória Miníma. Enterobactérias. Fitoterapia. Tratamento alternativo.

\section{USE OF EXTRACTS PLANTS IN COMBATING Escherichia coli CEPAS CAUSERS OF BOVINE NEONATAL DIARRHEA}

SUMMARY: The present study evaluated the use of extracts plants to control Escherichia Coli causing bovine neonatal diarrhea. Two strains of $E$. coli isolated from neonatal diarrhea samples were used. After identification of the bacterium, antimicrobial susceptibility was verified in vitro, followed by the calculation of the multiple antimicrobial resistance index (IRMA). The ethanolic extracts of: Guava, Pitanga, Earl Fruit, Acerola, Soursop, Pomegranate, Neem, Jenipapo, Lychee, Tamarindo, Jambo and Cider were tested. The minimum inhibitory concentration (MIC) of the extracts was determined using the plate microdilution method, where they were tested at various concentrations. The minimum bactericidal concentration (MBC) was determined after obtaining the minimum inhibitory concentration results, and then the survival curve was calculated. Both strains tested showed higher resistance to antibiotics Ceftazidime, Amicacin, Tobramycin, Tetracycline, Amoxicillin + Clavulanate, Cefoxitin and Cefotaxime and showed multidrug resistance. Regarding MIC and MBC, the extracts that showed antibacterial action were Pitanga, Tamarindo, Pomegranate, Jambo and Jenipapo. When the survival curve was evaluated, the extracts of Pitanga, Tamarindo, Pomegranate stood out against the two studied pathogens. It was concluded that the E. coli strains tested showed multiresistance, which demonstrates the indiscriminate use of

\footnotetext{
1 ORCID - http://orcid.org/0000-0003-2476-0170

2 ORCID - http://orcid.org/0000-0002-8084-8014

3 ORCID - http://orcid.org/0000-0002-3662-120X

4 ORCID - http://orcid.org/0000-0002-2110-2028

5 ORCID - http://orcid.org/0000-0001-8621-3338
} 
antibiotics, and that the use of extracts plant extracts was effective in the concentrations studied and could be used as alternative treatments against bovine neonatal diarrhea caused by E. coli.

Keywords: Minimal Inhibitory Concentration, Enterobacteria, Phytotherapy, Alternative Treatment.

\section{INTRODUÇÃO}

A patologia de maior importância que afeta os bezerros após o nascimento é a diarreia. Estima-se que mais de 50\% das mortes de bezerros estejam relacionadas a esta síndrome. Além de causar elevada morbidade pode também aumentar a susceptibilidade dos animais a diversas outras infecções, retardar o desenvolvimento e em casos extremos levar a morte. As perdas econômicas também são elevadas devido aos custos com tratamento e profilaxia (EMBRAPA, 2016).

Os principais patógenos associados à diarreia neonatal bovina são de origem bacteriana, dentre eles, a Salmonella spp., Escherichia coli e Clostridium perfringens tipo C. A Escherichia coli é o agente mais comumente encontrado, sendo descrita como uma bactéria gram-negativa, anaeróbia facultativa, da família Enterobacteriaceae que habita o intestino de seres humanos e animais geralmente sem causar danos (NATARO; KAPER 1998).

Mesmo que a maioria das cepas de E. coli vivam no ambiente intestinal de forma passiva, algumas cepas desta bactéria são extremamente patogênicas devido a capacidade de invadir as células do intestino e liberarem toxinas, podendo causar infecções entéricas graves (NATARO; KAPER 1998).

Para o tratamento destas infecções, tem-se como prática o uso de antimicrobianos. A utilização de forma adequada destes fármacos, no que diz respeito a dosagem e intervalos de administração nem sempre são realizados de maneira correta. Desta forma, o desenvolvimento de resistência antimicrobiana pode ocorrer e gerar graves transtornos a saúde pública (COSTA et al., 2014; IÇEN et al., 2013).

Devido aos problemas de resistência bacteriana, métodos alternativos vêm sendo estudados, dentre eles a utilização de extratos de plantas e ervas medicinais, fitoterapia e terapia homeopática. O uso destes tratamentos nas diversas atividades da agropecuária tem sido encorajado, porém, a implantação em sistemas convencionais ainda é desfavorável devido à falta de informação na literatura sobre a eficácia destes tratamentos (PEIXOTO, et al. 2009).

Diante deste fato, estudos sobre o uso de extratos vegetais vem ampliando-se dentro da saúde animal. Na pecuária agroecológica, o uso de plantas com fins antimicrobianos tem sido amplamente estudado (GONÇALVES, et al. 2013). Assim, o presente trabalho teve como 
objetivo avaliar o uso de extratos etanólicos de plantas frutíferas no controle de cepas selvagens de Escherichia coli causadoras de diarreia neonatal bovina.

\section{MATERIAL E MÉTODO}

A presente pesquisa foi desenvolvida no laboratório de Microbiologia da Universidade Brasil, Campus Fernandópolis, São Paulo. Foram utilizadas duas cepas de E. coli isoladas de amostras de diarreia neonatal provenientes de propriedades leiteiras localizadas na Região Noroeste Paulista. Estas amostras estavam armazenadas sob refrigeração no referido laboratório.

Após a confirmação da identificação da bactéria com uso de testes bioquímicos e morfológicos (WINN, 2008), foi realizada a verificação da susceptibilidade antimicrobiana in vitro, por meio do método de Kirby Bauer Modificado. Foram avaliados os antimicrobianos: ampicilina $(10 \mu \mathrm{g})$; azitromicina $(15 \mu \mathrm{g})$; ciprofloxacina $(5 \mu \mathrm{g})$; clindamicina $(2 \mu \mathrm{g})$; cloranfenicol $(30 \mu \mathrm{g})$; eritromicina $(15 \mu \mathrm{g})$; gentamicina $(10 \mu \mathrm{g})$; oxacilina $(1 \mu \mathrm{g})$; cefoxitina $(30 \mu \mathrm{g})$; linezolida $(30 \mu \mathrm{g})$; penicilina $\mathrm{G}(10 \mu \mathrm{g})$; sulfazotrim $(25 \mu \mathrm{g})$; rifampicina $(5 \mu \mathrm{g})$; tetraciclina $(30 \mu \mathrm{g}) \mathrm{e}$ vancomicina $(30 \mu \mathrm{g})$. Os resultados foram interpretados de acordo com parâmetros préestabelecidos (CLSI, 2012).

O cálculo do índice de resistência múltipla aos antimicrobianos (IRMA) foi realizado por meio da razão entre o número de antibióticos aos quais o isolado foi resistente e o número de antibióticos ao qual o isolado foi exposto. Quando o IRMA é superior a 0,2 caracteriza-se multirresistência (KRUMPERMAN, 1983).

Para verificação da ação antibacteriana in vitro, foram testados os extratos etanólicos das seguintes plantas do herbário da Universidade Brasil, Campus Fernandópolis: Goiaba (Psidium guajava L.), Pitanga (Eugenia uniflora L.), Fruta do conde (Annona squamosa L.), Acerola (Malpighia punicifolia L.), Graviola (Annona muricata L.), Romã (Punica granatum L.), Neem (Azadirachta indica A. Juss.), Jenipapo (Genipa americana L.), Lichia (Litchi chinensis), Tamarindo (Tamarindus indica L.), Jambo (Syzygium jambos L.), Cidra (Citrus medica L).

As folhas de cada planta foram lavadas com água destilada e, o material seco a temperatura ambiente durante 24 horas. Após, o material vegetal foi colocado em estufa com circulação de ar forçado a $40^{\circ} \mathrm{C}$, e posteriormente foi triturado. De cada planta utilizou-se $100 \mathrm{~g}$ para extração hidroalcóolica em etanol 70\% (v/v), seguido de agitação a 200 rpm em temperatura ambiente por 3 horas. Em seguida o extrato bruto foi produzido por filtração. $\mathrm{O}$ extrato filtrado foi levado a temperatura de $45^{\circ} \mathrm{C}$ por um período de duas semanas para evaporação do solvente (DUARTE et al., 2004).

Para o preparo do inóculo, culturas de 24 horas em meio ágar TSA foram transferidas para meio triptecaseina broth $(\mathrm{Oxoid} \AA)$ e incubadas a $37^{\circ} \mathrm{C}$ por 24 horas. A suspensão bacteriana foi 
diluída em solução salina estéril $(\mathrm{NaCl} 0,85 \%)$ até atingir a turbidez correspondente ao tubo 0,5 da escala de Mac-Farland, equivalente à concentração de $1,5 \times 10^{8} \mathrm{UFC} / \mathrm{mL}$.

A concentração inibitória mínima (CIM) dos extratos foi determinada seguindo os protocolos do CLSI (2012), utilizando-se o método de microdiluição em placas. As concentrações dos extratos testados foram variadas sendo elas: $0,4 \%, 0,8 \%, 1,6 \%, 3,2 \%, 6,25 \%, 12,5 \%, 25 \%$, $50 \%$ e $100 \%$ e o controle negativo. Após incubação a $37^{\circ} \mathrm{C}$ por 24 horas a CIM foi determinada pela adição, em cada amostra, do corante 2,3,5 -Triphenyltetrazolium Chloride, no volume de 50 $\mu \mathrm{L}$. A concentração inibitória mínima foi considerada como a menor concentração de extrato capaz de inibir o desenvolvimento bacteriano.

Para determinação da concentração bactericida mínima (CBM) foram transferidos $100 \mu \mathrm{L}$ de cada poço para placas de Petri contendo TSA, incubados a $37^{\circ} \mathrm{C}$ por $24 \mathrm{~h}$. A CBM, foi considerada a concentração que não apresentou crescimento bacteriano.

Após obtenção da CBM, a mesma foi utilizada para avaliar o crescimento bacteriano na presença dos extratos em função do tempo, determinando-se a curva de sobrevivência. Para isso, foram transferidos $100 \mu \mathrm{L}$ de cada poço, de acordo com a CBM pré-determinada, para placas de Petri contendo TSA. As amostras foram retiradas a cada 10 minutos por um período de 100 minutos. Em seguida as placas foram incubadas a $37^{\circ} \mathrm{C}$ por $24 \mathrm{~h}$. Após a incubação foi realizada a contagem de colônias. Este procedimento foi realizado em triplicata.

Todos os resultados obtidos foram tabulados e avaliados estatisticamente como tipo parcelas subdivididas no tempo (Split Plot), no delineamento inteiramente ao acaso. Todas as análises estatísticas foram realizadas no Software Minitab®, versão 18.1.

\section{RESULTADO E DISCUSSÃO}

Com relação aos resultados deste trabalho referentes a verificação da susceptibilidade antimicrobiana in vitro, as duas cepas testadas apresentaram maior resistência aos antibióticos Ceftazidima, Amicacina, Tobramicina, Tetraciclina, Amoxicilina + clavulanato, Cefoxitina e Cefotaxima. Os que demonstraram maior eficácia foram Cefepime e Sulfametoxazol + Trimetoprim. Além disso, esta pesquisa pode demonstrar que as duas amostras apresentaram IRMA acima de 0,2, o que determina multirresistência.

A multirresistência apresentada por bactérias provoca sério risco para a saúde pública pois atrapalha a eficiência dos tratamentos de doenças em seres humanos e animais. A maior ocorrência de multirresistência acontece principalmente em bactérias isoladas de animais de produção, devido ao uso indiscriminado de antibióticos aliado a casos de subdosagens, interrupção do tratamento assim que o animal apresenta melhora clínica e também a ausência da 
realização de diagnósticos e de teste de susceptibilidade bacteriana antes da instituição do tratamento (COELHO et al., 2007).

Dados semelhantes aos encontrados nesta pesquisa foram relatados por vários autores, dentre eles, na pesquisa realizada por Vargas Junior et al. (2017), que apontaram multirresistência de $E$. coli isoladas de diarreia neonatal bovina, em que $93 \%$ das amostras avaliadas demonstraram resistência a penicilina (10mg) e $80 \%$ a tetraciclina $(30 \mathrm{mg})$. Já em pesquisa realizada por Rigobelo et al. (2006), foi detectado resistência a pelo menos dois antimicrobianos em 100\% das bactérias isoladas de amostras de diarreia avaliadas provenientes de rebanhos leiteiros do estado de São Paulo, e que o maior índice de resistência foi frente a cefalotina $(46,1 \%)$ e tetraciclina $(45,7 \%)$.

Adicionalmente, Oliveira Filho et al. (2007) apontaram resistência a tetraciclina (30,4\%) e a ampicilina $(31,9 \%)$ em E. coli isoladas de diarreia neonatal de bezerros de corte provenientes do estado de Mato Grosso. Embora os dados encontrados com relação a porcentagem de resistência e tipos de antibióticos analisados sejam diferentes, ficou evidente nesses estudos a ocorrência de resistência bacteriana aos antimicrobianos, o que pode estar relacionado ao uso indiscriminado destes fármacos em propriedades rurais. Assim, é importante fazer uso de medidas de controle eficazes que visem a diminuição do uso de antibióticos, para que haja redução do aparecimento de microrganismos resistentes.

Devido a utilização indiscriminada e/ou incorreta de antibióticos, seu uso no tratamento de doenças bacterianas está sendo questionado. O aumento de bactérias que não apresentam susceptibilidade as classes de antibióticos cresce cada dia mais, desta forma, a busca pelo tratamento alternativo está em evidencia (DOEHRING; SUNDRUM, 2016).

A susceptibilidade a antimicrobianos também pode ser determinada por meio da avaliação da Concentração Inibitória Mínima (CIM), sendo esta a mínima concentração do produto capaz de afetar o patógeno de maneira efetiva, inibindo seu crescimento, porém com apresentação mínima de crescimento na subcultura. Este método é importante pois por meio dele pode-se obter a concentração mínima da substância a ser utilizada no animal para combater a enfermidade, evitando com isso o uso indiscriminado (CLSI, 2012).

Nesta pesquisa testou-se o uso de extratos etanólicos de plantas para o controle de E. coli por meio da determinação da CIM. Os resultados obtidos em relação ao teste de eficácia dos extratos frente as cepas de E. coli avaliadas, estão descritos na Tabela 1. 
Tabela 1 - Concentração Inibitória Mínima (CIM) de extratos etanólicos de plantas frente a cepas selvagens de E. coli.

\begin{tabular}{lcc}
\hline & \multicolumn{2}{c}{ CIM (\%) } \\
\cline { 2 - 3 } EXTRATO & CEPA:1 & CEPA:2 \\
& & \\
\hline Jenipapo & 25 & 50 \\
Pitanga & 3,2 & 12,5 \\
Jambo & 25 & 25 \\
Tamarindo & 6,25 & 12,5 \\
Romã & 6,25 & 6,25 \\
\hline
\end{tabular}

Fonte: Elaborada pelos autores

Referente a concentração inibitória mínima dos extratos quando testados contra cepas selvagens de E. coli, destacou-se os extratos de Pitanga, Tamarindo e Romã, pois inibiram o crescimento da bactéria em concentrações baixas, $12,5 \%, 12,5 \%$ e $6,25 \%$, respectivamente. Os extratos de Goiabeira, Fruta do Conde, Acerola, Graviola, Lichia, Neem e Cidra, não demonstraram efeito bactericida. Este fato pode estar relacionado a existência de estruturas da parede bacteriana que permite ou não a entrada de substâncias na bactéria. Além disso, alguns extratos podem conter substâncias que penetram mais facilmente por essa parede, interferindo na ação sobre o patógeno (BERTINI et al., 2005).

Outros autores já determinaram ações antibacteriana de extratos etanólicos de plantas contra E. coli. Delgado et al. (2019) relataram a eficácia do extrato etanólico de Gossypium hirsutum L.; Santos (2018), detectou a ação de Chenopodium ambrosioides L. (mastruz), Cymbopogon citratus (DC.) Stapf (Capim santo) e a Lippia alba (Mill.) N. E. Brown (Ervacidreira); e Costa el at. (2006) citaram a eficiência do extrato de casca de Amburana cearenses contra cepas de E. coli.

O uso de extratos de plantas para controle de patógenos é muito frequente, pois é um produto que possui inúmeras vantagens, dentre elas não deixa resíduo nos alimentos, não provocam efeitos colaterais, são bem mais baratos que os fármacos convencionais e além disso não agridem o meio ambiente (DOEHRING; SUNDRUM, 2016).

Após a obtenção da CIM, foi realizado o teste para verificação da Concentração Bactericida Mínima (CBM), concentração esta determinada como a menor dose dos extratos que visualmente apresentou inibição de crescimento e que na subcultura também não apresentou crescimento bacteriano. Os dados obtidos estão descritos na Tabela 2. 
Tabela 2 - Concentração Bactericida Mínima (CBM) de extratos etanólicos de plantas frente a cepas selvagens de E. coli.

\begin{tabular}{lcc}
\hline & \multicolumn{2}{c}{ CBM (\%) } \\
\cline { 2 - 3 } EXTRATO & CEPA 1 & CEPA 2 \\
\hline Jenipapo & 50 & 50 \\
Pitanga & 6,25 & 12,5 \\
Jambo & 25 & 25 \\
Tamarindo & 12,5 & 12,5 \\
Romã & 6,25 & 12,5 \\
\hline
\end{tabular}

Fonte: Elaborada pelos autores

Esta análise permitiu determinar as CBM para cada um dos extratos etanólicos avaliados, destacando a eficácia do extrato de Romã, Tamarindo e Pitanga frente aos dois patógenos avaliados, pois anulou a carga microbiana em concentrações de $12,5 \%$.

É possível observar que a contagem microbiana com a utilização da concentração de $25 \%$ surtiu efeito positivo no que se refere ao efeito bactericida do extrato de Jambo, sendo esse considerado também um extrato etanólico eficaz, porém com utilização em concentração maior. Assim como o extrato de Jenipapo, que demonstrou maior eficácia na concentração de 50\%.

Em um trabalho realizado para verificar a atividade antimicrobiana in vitro de extratos de plantas do bioma caatinga em isolados de E. coli, foram utilizados os extratos das plantas: Amburana cearenses, Encholirium spectabile, Hymenaea courbaril, Neoglaziovia variegata e Selaginella convoluta. Apresentaram atividade antimicrobiana, com as seguintes médias de concentração bactericida mínima $(\mathrm{CBM}): 138,75 \mu \mathrm{g} / \mathrm{mL}$ (E. spectabile); 175, $28 \mu \mathrm{g} / \mathrm{mL}(\mathrm{N}$. variegata); 128, $36 \mu \mathrm{g} / \mathrm{mL}$ (A. cearenses); 127, $71 \mu \mathrm{g} / \mathrm{mL}$ (H. courbaril); 129, $33 \mu \mathrm{g} / \mathrm{mL}$ (S. convoluta) (FERNANDES et al., 2015).

Com relação ao comportamento das cepas de E. coli avaliadas por meio da curva de sobrevivência bacteriana de acordo com o tempo de exposição aos extratos, os resultados estão expressos nas Tabelas 3 e 4. 
Tabela 3: Médias da contagem de E. coli da Cepa Selvagem 1 para os tempos avaliados utilizando a CBM de cada extrato etanólico efetivo.

\begin{tabular}{cccccc}
\hline $\begin{array}{c}\text { Tempo } \\
(\min )\end{array}$ & $\begin{array}{c}\text { Jenipapo } \\
(50 \%)\end{array}$ & $\begin{array}{c}\text { Pitanga } \\
(6,25 \%)\end{array}$ & $\begin{array}{c}\text { Jambo } \\
(25 \%)\end{array}$ & $\begin{array}{c}\text { Tamarindo } \\
(12,5 \%)\end{array}$ & $\begin{array}{c}\text { Romã } \\
(6,25 \%)\end{array}$ \\
\hline 0 & $1,4.10^{5}$ & $1,2.10^{5}$ & $1,3.10^{6}$ & $1,0.10^{5}$ & $1,3.10^{6}$ \\
10 & $1,7.10^{3}$ & $1,1.10^{3}$ & $1,1.10^{5}$ & $1,2.10^{4}$ & $1,2.10^{5}$ \\
20 & $1,2.10^{3}$ & $1,4.10^{2}$ & $1,2.10^{4}$ & $1,1.10^{3}$ & $1,4.10^{3}$ \\
30 & $2,2.10^{2}$ & $1,0.10^{2}$ & $2,1.10^{3}$ & $3,0.10^{2}$ & $1,5.10^{1}$ \\
40 & $1,0.10^{2}$ & $1,0.10^{1}$ & $2,5.10^{2}$ & $1,0.10^{1}$ & $1,0.10^{1}$ \\
50 & $3,1.10^{1}$ & 4,0 & $3,0.10^{1}$ & 3,0 & 4,0 \\
60 & $1,1.10^{1}$ & 0,0 & $1,5.10^{1}$ & 0,0 & 0,0 \\
70 & 2,0 & 0,0 & 5,0 & 0,0 & 0,0 \\
80 & 0,0 & 0,0 & 2,0 & 0,0 & 0,0 \\
90 & 0,0 & 0,0 & 0,0 & 0,0 & 0,0 \\
100 & 0,0 & 0,0 & 0,0 & 0,0 & 0,0 \\
\hline
\end{tabular}

Fonte: Elaborada pelos autores

Tabela 4: Médias da contagem de E. coli da Cepa Selvagem 2 para os tempos avaliados utilizando a CBM de cada extrato etanólico efetivo.

\begin{tabular}{cccccc}
\hline $\begin{array}{c}\text { Tempo } \\
(\min )\end{array}$ & $\begin{array}{c}\text { Jenipapo } \\
(50 \%)\end{array}$ & $\begin{array}{c}\text { Pitanga } \\
(12,5 \%)\end{array}$ & $\begin{array}{c}\text { Jambo } \\
(25 \%)\end{array}$ & $\begin{array}{c}\text { Tamarindo } \\
(12,5 \%)\end{array}$ & $\begin{array}{c}\text { Romã } \\
(12,5 \%)\end{array}$ \\
\hline 0 & $1,2.10^{5}$ & $1,2.10^{6}$ & $1,2.10^{6}$ & $1,8.10^{5}$ & $1,2.10^{6}$ \\
10 & $1,2.10^{3}$ & $1,4.10^{5}$ & $1,3.10^{5}$ & $1,4.10^{4}$ & $1,1.10^{5}$ \\
20 & $1,2.10^{2}$ & $1,2.10^{4}$ & $1,3.10^{4}$ & $1,3.10^{3}$ & $1,8.10^{3}$ \\
30 & $4,2.10^{1}$ & $1,5.10^{3}$ & $1,5.10^{3}$ & $2,0.10^{2}$ & $1,9.10^{1}$ \\
40 & $1,3.10^{1}$ & $1,0.10^{2}$ & $1,3.10^{2}$ & $1,2.10^{1}$ & $1,4.10^{1}$ \\
50 & 8,0 & $1,1.10^{1}$ & $2,0.10^{1}$ & 2,0 & 9,0 \\
60 & 3,0 & 0,0 & $1,0.10^{1}$ & 0,0 & 3,0 \\
70 & 0,0 & 0,0 & 3,0 & 0,0 & 0,0 \\
80 & 0,0 & 0,0 & 0,0 & 0,0 & 0,0 \\
90 & 0,0 & 0,0 & 0,0 & 0,0 & 0,0 \\
100 & 0,0 & 0,0 & 0,0 & 0,0 & 0,0 \\
\hline
\end{tabular}

Fonte: Elaborada pelos autores

Quando analisada a cepa selvagem 1, a mesma demonstrou-se susceptível ao extrato etanólico de Pitanga, Tamarindo e Romã, em suas respectivas CBM, pois com 60 minutos de exposição o crescimento bacteriano foi anulado.

Os extratos etanólicos de Jenipapo e Jambo, também apresentaram resultados satisfatórios, porém, com eficácia menor, já que anularam o crescimento bacteriano nos tempos de 80 e 90 minutos, respectivamente (Figura 1). 
Figura 1: Perfil da curva de sobrevivência de E. coli Cepa Selvagem 1 para os tempos avaliados utilizando a CBM de cada extrato etanólico avaliado.

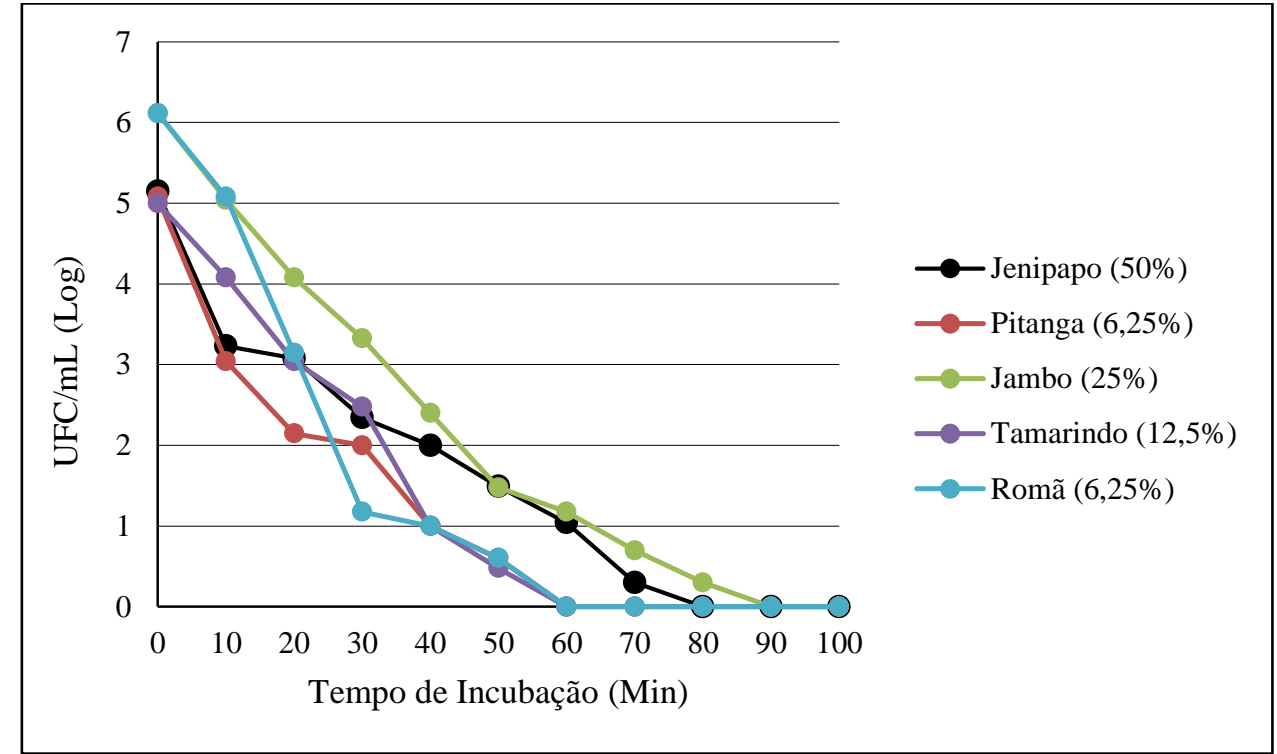

Fonte: Elaborada pelos autores

Quando testados contra a Cepa Selvagem 2, os extratos demonstraram praticamente a mesma eficácia, reforçando novamente a ação do extrato de Pitanga e Tamarindo, que anulou o crescimento bacteriano novamente após 60 minutos de exposição (Figura 2).

Figura 2: Perfil da curva de sobrevivência de E. coli Cepa Selvagem 2 para os tempos avaliados utilizando a CBM de cada extrato etanólico avaliado.

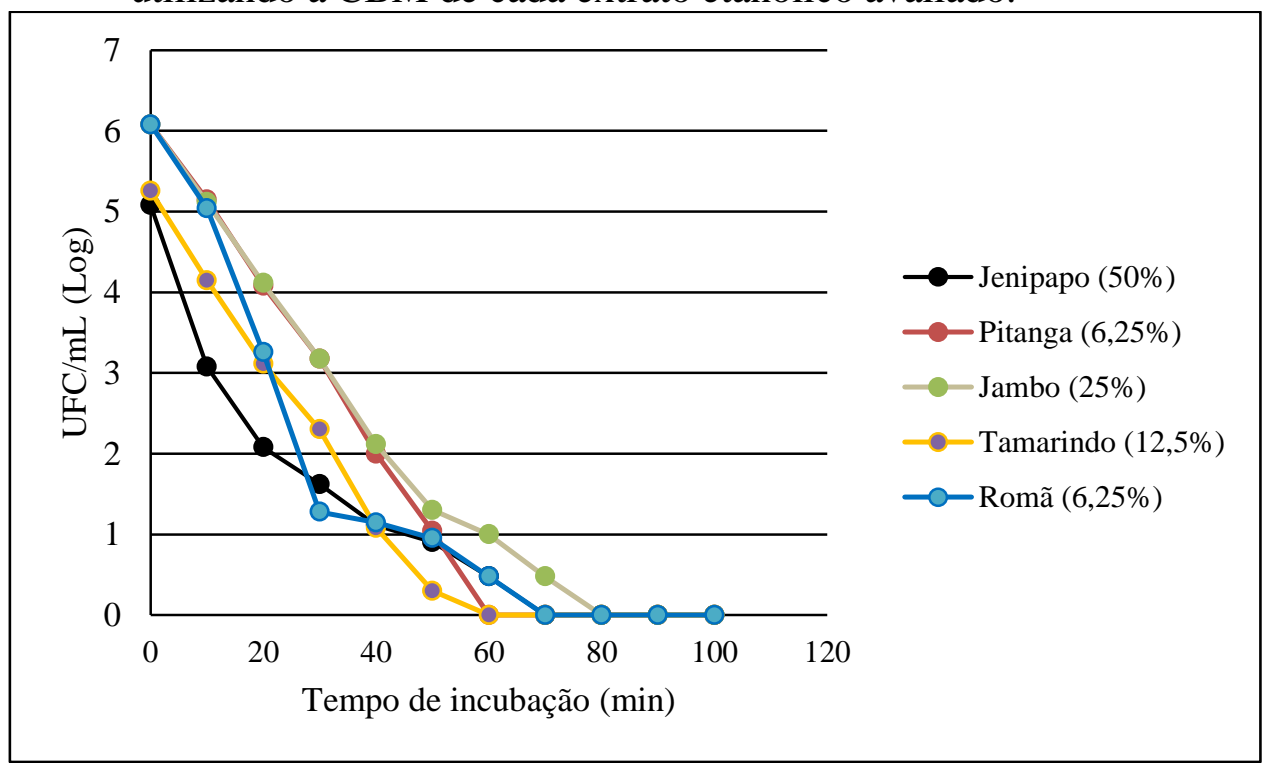

Fonte: Elaborada pelos autores

Quando avaliada a curva de sobrevivência bacteriana em função do tempo, foi possível evidenciar o efeito inibidor dos extratos nas concentrações determinadas nesta pesquisa, sendo o efeito bactericida demonstrado quando a contagem bacteriana chegou a zero. 
Extratos etanólicos da raiz de B. pilosa (picão preto), demonstraram ação bactericida contra bactérias gram negativas, dentre elas a E. coli, com CIM variando de 5,0 a 10,0 mg/mL, enquanto o extrato aquoso não demonstrou atividade (ASHAFA; AFOLAYAN, 2009).

O tratamento da diarreia neonatal de bezerros se baseia na antibioticoterapia, e por ser uma síndrome de elevada ocorrência, o uso ostensivo e inadequado destes fármacos proporciona resistência bacteriana a diversos princípios ativos. Por isso a busca efetiva do uso de compostos naturais para tratamento desta síndrome, vem sendo estimulada (TORTORA; FUNKE; CASE, 2012).

A cada ano que passa, o desenvolvimento dos saberes dos seres humanos com relação a saúde humana e animal tem trazido base cientifica ao uso popular das plantas. Por isso, a fitoterapia constitui alternativa econômica e eficaz em relação aos medicamentos alopáticos e deve ser mais estudada para ter aplicação efetiva na prática pois os extratos testados in vitro neste trabalho apresentaram resultados satisfatórios frente a bactéria avaliada.

\section{CONCLUSÃO}

Após a execução deste trabalho concluiu-se que as duas cepas de E. coli testadas apresentaram multirresistência, o que demonstra o uso indiscriminado de antibióticos em propriedades rurais.

O uso de extratos de plantas para controle de E. coli provenientes de casos de diarreia neonatal bovina mostrou-se eficaz nas concentrações pesquisadas, sendo que os extratos de Pitanga, Romã e Tamarindo demonstraram melhor eficácia. Além disso, sugere-se a utilização destes extratos por 60 minutos para inativação da bactéria.

Portanto a utilização de tratamentos alternativos contra diarreia neonatal bovina causada por E. coli pode se tornar viável, porém novas pesquisas devem ser realizadas por meio de testes in vivo.

\section{REFERENCIAS}

ASHAFA, A.O.T.; AFOLAYAN, A. J. Screening the root extracts from Bidens pilosa L. var.radiata (Asteraceae) for antimicrobial potentials. Journal of Medicinal Plants Research, v. 3, n. 8, p. 568-572, 2009.

BERTINI, L.M. et al. Perfil de sensibilidade de bactérias frente a óleos essenciais de algumas plantas do Nordeste do Brasil. Revista Infarma, v.17, n.314, p.80-3, 2005.

CLSI - Clinical and Laboratory Standards Institute. Performance standards for antimicrobial susceptibility testing. Twenty-second Informational Suplement M100- s22, Wayne, PA. v.32, n.3, p.1-184, 2012 
COELHO, S.M.O.; GOMES, L.P.; MORAES, R.A.M.; et al. Mapeamento do perfil de resistência e detecção do gene mecA em Staphylococcus aureus e Staphylococcus intermedius oxacilina-resistentes isolados de espécies humanas e animais. Ciência Rural, v.37, n.1, p.195200, 2007.

COSTA, K.O.; ALZAMORA FILHO, F.; COSTA, J.N. Fatores de virulência das amostras de Escherichia coli isoladas de bezerros com diarreia na região de Feira de Santana, Bahia. 2014. 8 f. Tese- Medicina Veterinária, Universidade Estadual de Feira de Santana, Feira de Santana, 2014.

COSTA, M.M.; SILVA, M.S.; SPRICIGO, D.A.; et al. Caracterização epidemiológica, molecular e perfil de resistência aos antimicrobianos de Escherichia coli isoladas de criatórios suínos do sul do Brasil. Pesquisa Veterinária Brasileira, v. 26, n. 1, p. 5-8, 2006.

DELGADO, L.A. et al. Atividade Antibacteriana do Extrato Etanólico Bruto da Gossypium hirsutum L. contra Cepas de Klebsiella pneumoniae e Escherichia coli. Revista Eletrônica Acervo Saúde, v.11, n. 2, p.1-6, 2019.

DOEHRING, C.; SUNDRUM, A. Efficacy of homeopathy in livestock according to peerreviewed publications from 1981 to 2014. Veterinary Record. v.179, n.24, p.628, 2016.

DUARTE, M.C.T; FIGUEIRA G.M.; PEREIRA, B. et al. Atividade antimicrobiana de extratos hidroalcólicos de espécies da coleção de plantas medicinais CPQBA/UNICAMP. Revista Brasileira de Farmacognosia, v. 14, supl. 01, p. 06-08, 2004.

EMBRAPA. Empresa Brasileira de Pesquisa Agropecuária. Diarreia em bezerros leiteiros: Ocorrência e Tratamento. 2016. Disponível em: $<$ http://iepec.com/diarreia-em-bezerrosleiteiros-ocorrencia-e-tratamento/>. Acesso em: 24/03/2018.

FERNANDES, A.W.C. et al. Atividade antimicrobiana in vitro de extratos de plantas do bioma caatinga em isolados de Escherichia coli de suínos. Revista Brasileira de Plantas Medicinais, v.17, n.4, supl. III, p.1097-1102, 2015.

GONCALVES, C.L. et al. Actividad antibacteriana de los extractos de Cymbopogon citratus, Elionurus sp. y Tagetes minuta contra bacterias que causan mastitis. Revista Cubana de Plantas Medicinais, v. 18, n. 3, p. 487-494, 2013.

IÇEN, H.; ARSERIM, N. B.; IŞIK3, N.; ÖZKAN C.; Kaya, A. Prevalence of Four Enteropathogens with Immunochromatographic Rapid Test in the Feces of Diarrheic Calves in East and Southeast of Turkey. Pakistan Veterinary Journal, v.33, n.4, p.496-499, 2013.

KRUMPERMAN, P. H. Multiple Antibiotic Resistance Indexing of Escherichia coli to Identify High-Risk Sources of Fecal Contamination of Foods. Applied and Environmental

Microbiology, v.46, n.1, p. 165-170, 1983.

NATARO, J.P.; KAPER, J.B. Diarrheagenic Escherichia coli. Clinical Microbiology Review, v. 11, n. 1, p. 142-201, 1998.

OLIVEIRA FILHO, J.P.; SILVA, D.P.G.; PACHECO, M.D. et al. Diarreia em bezerros da raça Nelore criados extensivamente: estudo clínico e etiológico. Pesquisa Veterinária Brasileira, v. 27, n. 10, p.419-424, 2007. 
PEIXOTO, E.C.T.M. et al. Incidência de mastite bovina em animais homeopatizados. Revista do Instituto de Laticínios “Cândido Tostes”, v.64, n.367/368, p.66-71, 2009.

RIGOBELO, E.C.; GAMEZ, H.J.; MARIN, J.M.; et al. Virulence factors of Escherichia coli isolated from diarrheic calves. Arquivo Brasileiro de Medicina Veterinária e Zootecnia, v.58, n.3, p.305-310, 2006.

SANTOS, A.P.G. Avaliação da atividade antibacteriana das plantas medicinais utilizadas pelos agricultores do povoado de Escoval - BA. Trabalho de conclusão de curso (Graduação) Faculdade Maria Milza, Governador Mangabeira, Bahia, 2018.

SILVA, M.T.N. et al. Atividade antibacteriana de óleos essenciais de plantas frente a linhagens de Staphylococcus aureus e Escherichia coli isoladas de casos clínicos humanos. Revista Brasileira de Plantas Medicinais, Botucatu, v.11, n.3, p.257-262, 2009.

TORTORA, G.J.; FUNKE, B.R., CASE, C.L. Microbiologia. Tradução: DA SILVA, A. M. 10 ed., Porto Alegre: Artmed, 2012. p. 280-751.

VARGAS JUNIOR, S.F. et al. Identificação de fatores de virulência de isolados de Escherichia coli oriundos de fezes de bezerros na região Sul do Brasil. Acta Scientiae Veterinariae, v. 45, 2017, pp. 1-6.

WINN, W. et al. Koneman: Diagnóstico microbiológico, texto e atlas colorido. 6.ed. Rio de Janeiro: Guanabara Koogan, 2008. 1760 p. 